\title{
The Development and Educational Application of Editable University Digital Museum
}

\author{
http://dx.doi.org/10.3991/ijoe.v11i1.3937 \\ Yang Yuhui, Zhang Hao and Youbin Jiang \\ Zhejiang University, Hangzhou, China
}

\begin{abstract}
Currently, in most university digital museums, there are problems with low immersion, and slow loading times as well as the impossibility of updating the 3D digital resources and extending their virtual exhibition space and changing style, leading to difficulty in management and being less effective in educational application. An editable university digital museum system was proposed and developed according to the learning theory and used in the Zhejiang University History Museum. In addition, the input and output efficiency of the system was compared with that of the university digital museum based on X3D. Finally, the editable university digital museum system was used in informal learning. The result indicated that the editable university digital museum system is superior to the traditional 3D digital museum in development speed as well as the immersive, management and learning effects.
\end{abstract}

Index Terms-Digital Museum, Web3D, X3D, Informal learning.

\section{INTRODUCTION}

Digital museums play an important role in education, science and research by recording the footprint of human civilization [1]. The development of traditional museums are limited to a great extent by the resources, space and funds, but the virtualization and networking of traditional museums can effectively save money and protect cultural heritage as well as share resources. Therefore, more attention is being paid to digital museums [2]. With the development of computer graphics and multimedia technology, the term digital museum was first proposed by Tsichritzis and Gibbs [3]. Digital museums can simulate a real museum in $3 \mathrm{D}$ through virtual reality technology. Web3d is a kind of virtual reality technology based on a 3D internet platform [4] that displays objects tangible in the real world on the internet and supports interaction between users and virtual objects [5]. Web3d originating from Virtual Reality Modeling Language ( VRML) in the internet can be traced back to the 1990s[6]. VRML had a new standard known as X3D in 2004[7]. As the VRML Association was renamed the Web3d Alliance, these technologies based on 3D Internet platform were named Web3D technology [8]-[9]. Representative software is Virtools, Unity3d, VRP, Java3d, etc [10].

Currently, most of the university digital museums lack immersiveness, as they were build as webpages and show exhibits by images (e.g., Tokyo University Digital Museum, Harvard Art Museums, Penn Museum and so on) [11]-[13]. Some university digital museums built by Web3d were difficult to manage, for example, the digital museum of Tsinghua University [14]. These problems include a long development cycle, slow loading, the impossibility of being edited freely [15]-[16], and challenges updating the $3 \mathrm{~d}$ heritage exhibits in a timely fashion in these digital museums, leading to wasted resources [17]-[19].

\section{THEORETICAL SUPPORT}

The cone of experience theory is that the more concrete and vivid the information is, the easier it is for the learners to understand and accept [20]. The constructivist learning theory is that learning is an active, contextualized process of constructing knowledge rather than acquiring it [21]. Knowledge is constructed based on personal experiences and hypotheses about the environment. Learners continuously test these hypotheses through social negotiation. Each person has a different interpretation and construction of the knowledge process. The learner is not a blank slate, but brings past experiences and cultural factors to a situation. The constructivist learning theory emphasizes that the subject of cognition is the student who actively constructs the sense of knowledge and the teacher just helps and promotes the construction. Therefore, an editable university digital museum is convenient for acquiring knowledge in informal learning, as it has vivid exhibits and flexible resources in the editing mode. Convenient maintenance, colorful content and an immersive educational environment are important evaluation indexes of a university digital museum. From the perspective of the system developers, an editable university digital museum is expected to meet different customers' needs, to avoid repetitiveness involved in building digital museums one by one, and to create the greatest economic benefit. Digital museum administrators urgently want to design the museum style, update the library resources, expand the scale of the exhibition hall, and manage the museum system according to their own needs instead of the developers'. From the perspective of visitors, new content such as the wonderful real-time activities and up-to-date information of collection resources are expected to be present in the digital museums when they visit.

According to the analyses above, an editable university digital museum system (EUDMS) was proposed based on Web3D virtual reality technology. The administrators can add, delete or search the information or exhibits of the digital museum. An editable university digital museum system can be applied to many types of digital museums and galleries to greatly save funds, human resources, digital resources and time developing a university digital museum. 
PAPER

The Development and Educational Application of Editable University Digital Museum

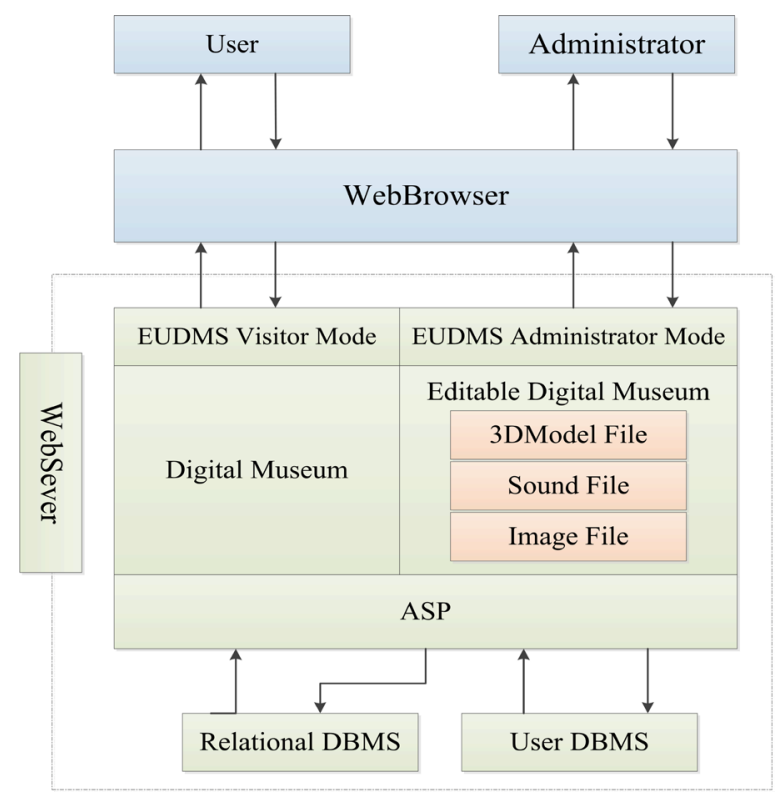

Figure 1. the operating principle of EUDMS

\section{OVERVIEW OF EUDMS}

From the perspective of users, an EUDMS is divided into two sections: the EUDMS Visitor Mode and an Administrator Mode. From the perspective of the network, an EUDMS is divided into two sections: servers and clients, as shown in Figure 1.

The operation principles of an EUDMS are: administrators access the Administrator Mode of the server-side with the help of the Internet and the web browser and then store the properties of the 3D model file, image file and text into the related Database Management System (DBMS) using an editable digital museum, DBMS and Active Server Page (ASP). The properties include the coordination, scale, texture, anchor, light and so on. The EUDMS visitor mode presents the various files in the database, which are stored in the digital museum by the administrator. Client-side users can browse the digital museum in a visitor mode through Explorer. ASP is used to load and display the EUDMS in the network; User DBMS is used to store the users' registration information and for administrator privileges. However, users cannot use the EUDMS Visitor Mode to edit the EUDMS based on the system's architecture.

\section{THE ARCHITECTURE OF EUDMS}

The EUDMS has two remarkable features: universality and editability, which can be used for many types of digital museum construction. Figure 2 shows the architecture model of EUDMS.

\section{A. EUDMS Administrator Mode}

The design of the EUDMS Administrator Mode mainly aims at updating exhibits and displaying information about the editable digital museum, which mainly includes the resource library construction. An administrator can edit the digital museum and save changed information.

\section{1)Repository}

Besides text, the 3D models, pictures, movies and sounds required by the EUDMS are all stored in the repository. The repository is constructed by administrators and visitors together to diversify the channels of resource acquisition. Administrators can upload 3D models, pictures, movies and sounds to the server-side repository in the EUDMS Administrator Mode. During the process of uploading, the resources can be saved and named by the administrators or named automatically by the system. In the repository, all kinds of uploaded resources are presented in different sections of the webpage to be conveniently used by the administrator. Internet pictures can be previewed in the repository by search filename, shown on the webpage of the system, and are applied to the editable digital museum.

\section{2)Editable Digital Museum}

The editable digital museum is the core of the EUDMS. The administrator integrates various resources from the repository into the editable digital museum and shows these resources to visitors through the digital museum. Functions of digital museum functions include changing the style of the museum, adding and removing 3D models, pictures, movies and sound; changing the property of the position, scale, and rotation of 3D model; displaying the exhibits' information; adding exhibit links; searching exhibits; and so on.

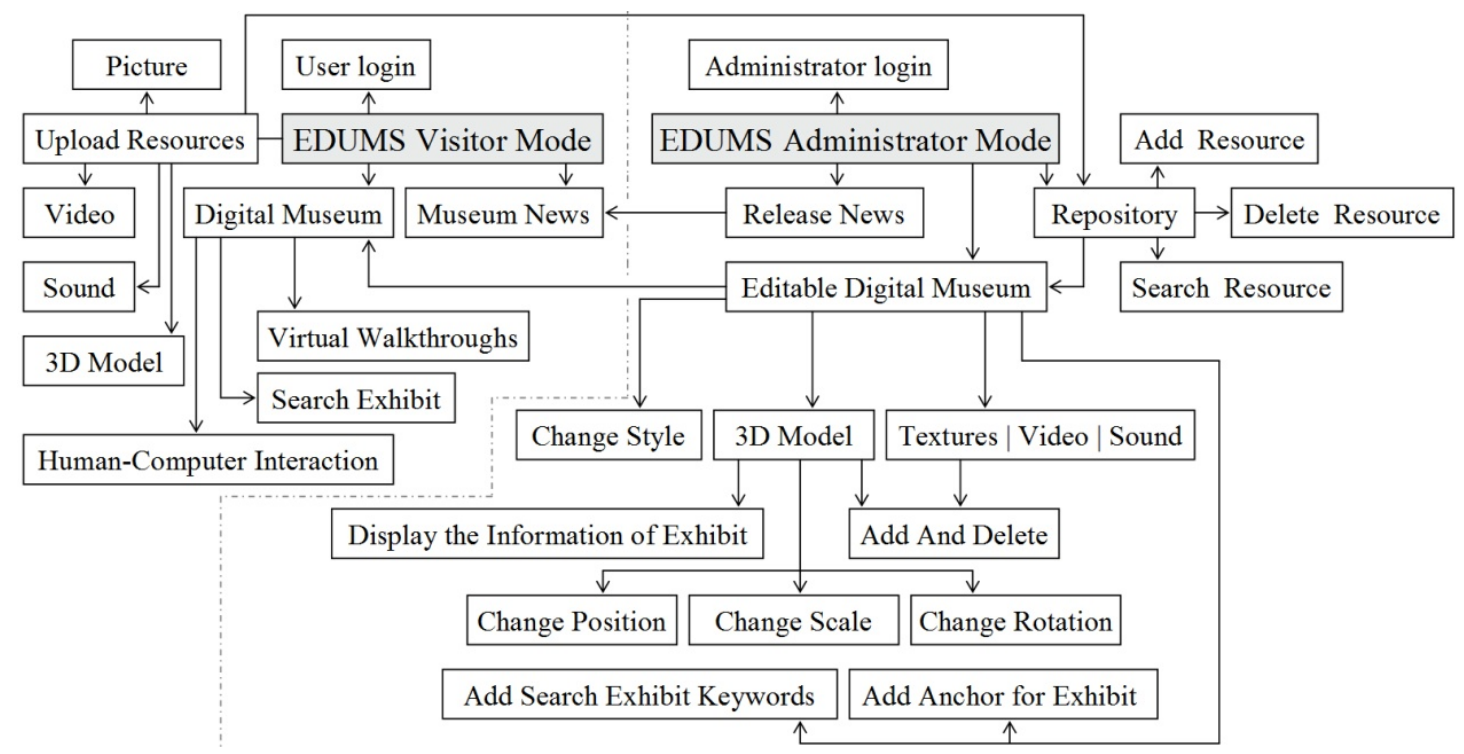

Figure 2. the architecture model of EUDMS 


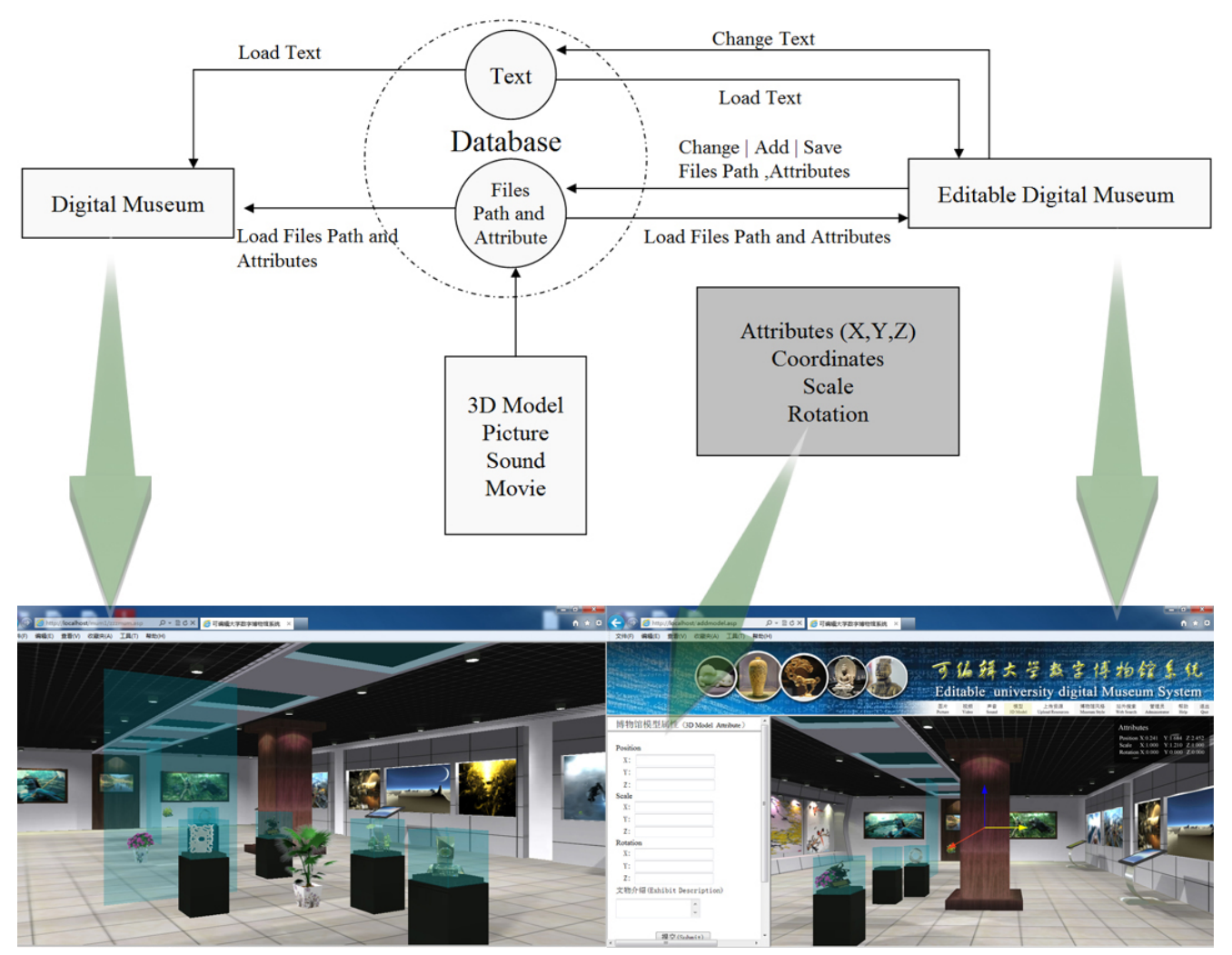

Figure 3. the realization of the EUDMS core function

Editable digital museums and digital museums load exhibits (3D models, pictures, sounds and movies) through the file paths and proportions that were stored in a database. File attribution includes coordinates, rotation and scale of the 3D model in the X, Y, Z directions. An administrator can edit file paths and attributes in an EUDMS Administrator Mode and store data to a database. Digital museums read file paths and attributes from the database, which was stored by administrator. Visitors browse exhibits through the digital museum in the EUDMS Visitor Modes s, as shown in Figure 3.

In an editable digital museum, administrators can add the appropriate information for exhibits to help visitors understand the heritage of the exhibits. Administrators can mark the 3D model resources uploaded by registered users as "user contribution." Administrators can add webpage links to exhibits to help visitors obtain more knowledge about the heritage. Also administrators can add keywords to the exhibits, which can provide convenience for visitors to search exhibits in the digital museum and to quickly acquire information from the exhibits.

\section{B. EUDMS Visitor Mode}

The EUDMS Visitor Mode mainly includes user registration, museum news, information displays, uploaded resources, virtual tours, human-computer interaction, and exhibit searches. Visitors can choose any route to visit the digital museum, search exhibits by keywords, observe exhibits from any angle, and get exhibits' commentator information through interaction with the virtual exhibits; an immersive experience can be enjoyed in the digital museum. In addition, visitors can contribute resources to the server by uploading 3D models, sounds, videos, and so on to enrich the repository.

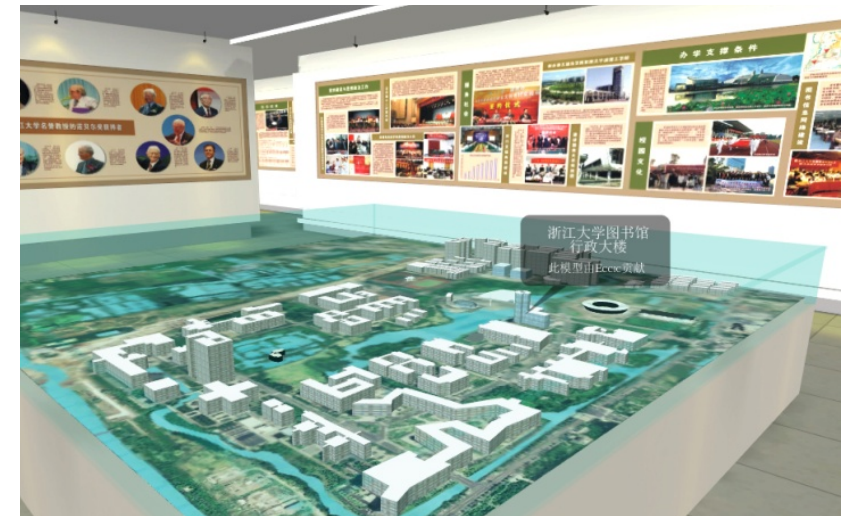

Figure 4. the 3D Model was donated by student

\section{COnSTRUCTION OF EUDMS}

The digital history museum of Zhejiang University was developed by EUDMS to provide a highly immersive environment for learning history and culture. In the digital history museum, an administrator can add pictures and 3D models and label the resource uploaded by students. As shown in Figure 4. Information about the user was presented in the label, which motivated the students to provide more resources for the administrator. This method increased the chances for the repository to acquire resources, leading to cooperation between the users and the administrator.

EUDMS provides great convenience for administrators to update exhibits in a digital history museum. Administrators and students can upload pictures, 3D models, sounds and movies to the repository. The administrator can add or delete resources in the repository that are displayed on different WebPages, as shown in Figure5. 


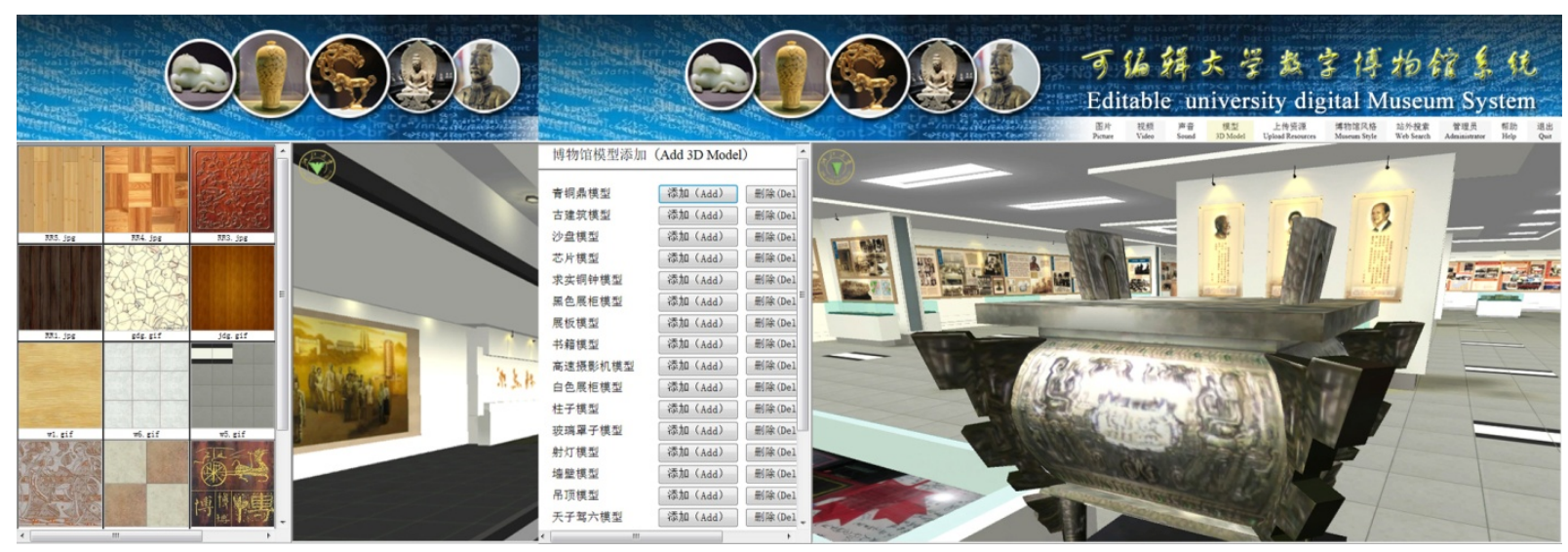

Figure 5. resources were displayed on different WebPages

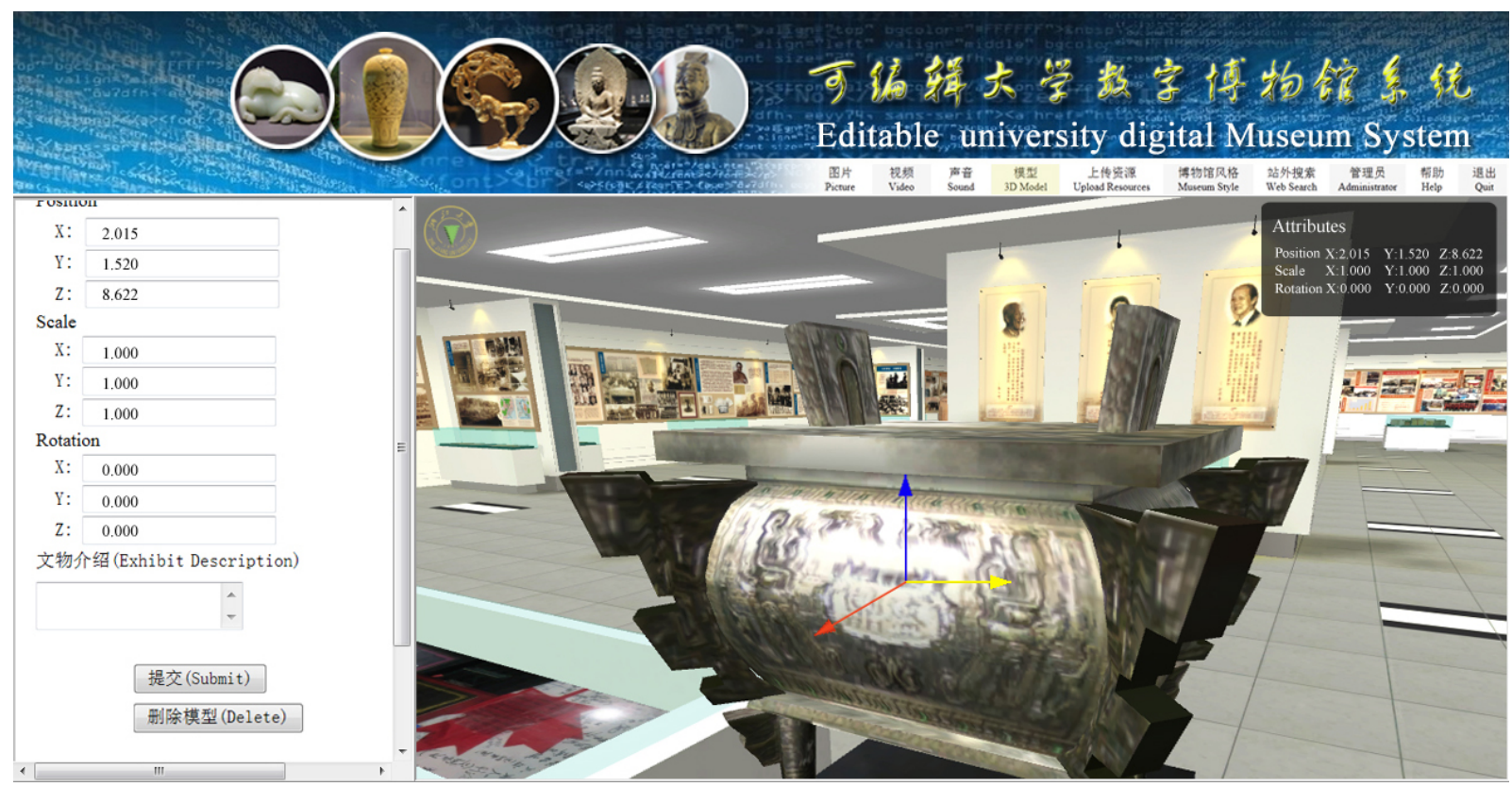

Figure 6. the attributes of 3D Model was changed

Professional skills of 3 dsmax, Program and virtual reality are not needed for administrators to complete adding, removing and changing of exhibit information, which saves manpower and shortens the time for developing a digital history museum. As shown in Figure 6. Another version of the digital history museum for Zhejiang University was developed by X3D (http: //xywh.zju.edu.cn/xsz/index. htm), according to the traditional mode of developing a digital museum online based on Web3D[22]-[25]. The digital history museum base on X3D does not have the function of online editing; therefore, developers were needed to modify the program for updating the resources when the software development project was finished. From the perspective of software development, the two versions of the digital history museums were compared, as shown in Table 1.

From Table I, we can see the advantages of an EUDMS in building a university digital museum: less difficulty in development, shortened processing cycle, easier to manage and maintain, and exhibits can be reused. Administrators can change the topic content of an exhibit from one to another quickly, which improves the speed of network resource processing and promotes the communication of digital resources.
TABLE I.

CONTRASTIVE ANALYSIS OF THE EUDMS AND X3D

\begin{tabular}{lcc}
\hline \multicolumn{1}{c}{ Name } & EUDMS & X3D \\
\hline Developer(person) & 1 & 1 \\
Development Cycle(day) & 1 & 15 \\
Load Time(second) & 32 & 50 \\
Difficulty & low & high \\
Update Resources & YES & NO \\
Manage and Maintain & Teacher or student & Professional people \\
Style Changing & YES & NO \\
\hline
\end{tabular}

\section{THE EDUCATIONAL APPLICATION OF EUDMS}

Users can build a university digital museum quickly through an EUDMS, which provides a highly immersive and interesting virtual learning environment for students. Ningbo Beilun Education Bureau built a digital educational museum for middle school students using an EUDMS. Yiwu Industrial and Commercial College carried out informal learning activities by developing a digital history museum and the school-based curriculum, as shown in Figure 7. The students participated in active learning, as the EUDMS provided a very interesting learning environment that stimulated their interest and initiative for learning. 
The definition of informal learning is the individual learning activities outside of the classroom without a teacher [26]. According to related research, $75 \%$ to $80 \%$ of the learning occurs in informal organizational activities [27]. A digital museum is a typical environment for informal learning, so the digital history museum of Zhejiang University was taken as the example in our research of informal learning for culture and history. The digital history museum was briefly introduced to the students in the classroom to carry out informal learning activities more conveniently. A randomized paired experimental design was conducted to assess the effects of the two versions of the museum in learning. Two groups of students from the same grade were selected; thirty persons (half boys and half girls) were in each group. One group was required to learn informally through the digital history museum of Zhejiang University based on the EUDMS, while the other used the digital history museum based on X3D.

In the digital history museum of Zhejiang University based on EUDMS, the students were required to log into the system by filling in their personal information when they visited, as shown in Figure 8. In the situational virtual environment, the students could freely select routes to visit the exhibits and could acquire history information about the cultural relic from related commentary. Any question about the cultural relic could be discussed with the teacher or other students in the history museum through a communication window, as shown in Figure 9. The mode of collaborative learning promoted the communication of information and knowledge understanding for students.

Some worksheets of each main theme in the museum could be opened by a hotlink. The worksheets were designed according to the key points of the theme to estimate the learning effect. The questions on the worksheets guided the students to write fictional stories according to some of the exhibits and history using their imagination, prediction, reasoning, and creativity. The stories could be recommended to the teacher or administrator and published in the history museum to attract student interest.

In the digital history museum of Zhejiang University based on X3D, the students could visit 3D exhibits and browse commentary without interaction with the teacher. The resources of this museum could not be edited or updated by the teacher without the help of the developers.

The learning effect was estimated through the worksheets and interviews were conducted with the two groups of students a week after the learning. The percent of students in three score levels is shown in Table II.

Fifteen boys and fifteen girls were selected from the same grade to experience the two different versions of the digital history Museum of Zhejiang University. The evaluation and feedback information of their experiences is shown in Table III.

As shown in Tables II and III, in informal learning more students thought the digital history museum based on the EUDMS was superior to the other in being immersive and interesting, offering management, and updating the amount of resources. The mode of resource co-construction by students and teachers stimulated the students' initiative and enthusiasm, leading to higher learning efficiency compared with the other group.

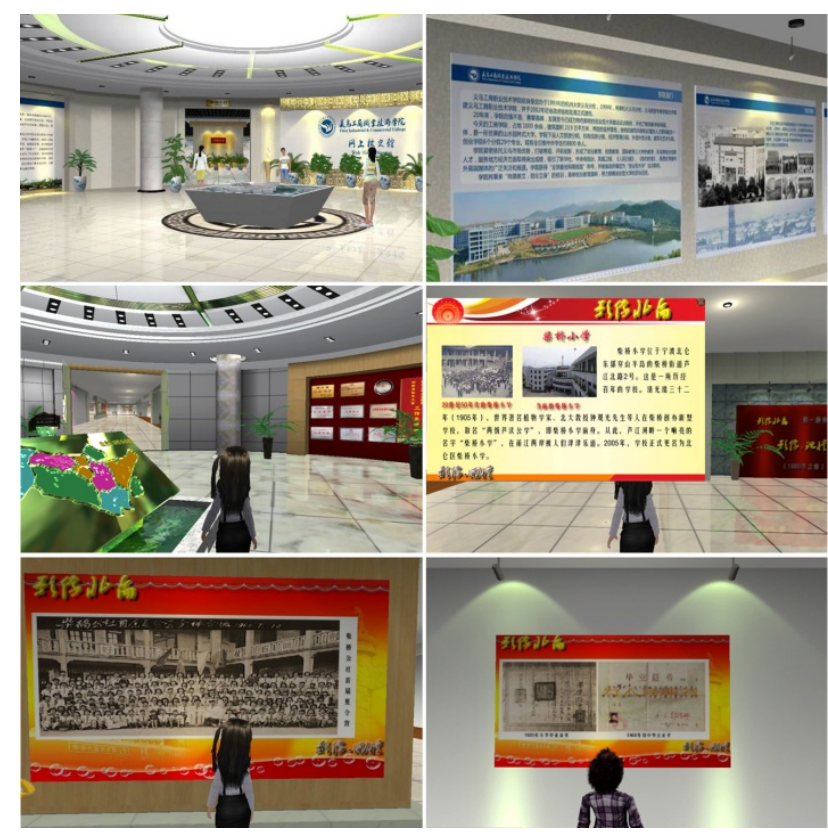

Figure 7. The educational application of digital museum based on EUDMS

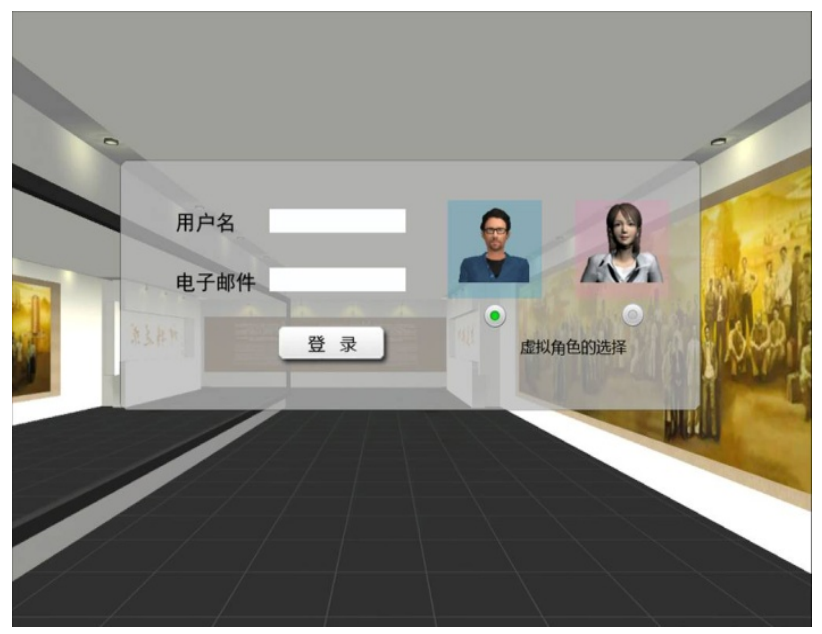

Figure 8. User login of the digital history museum of Zhejiang University base on EUDMS

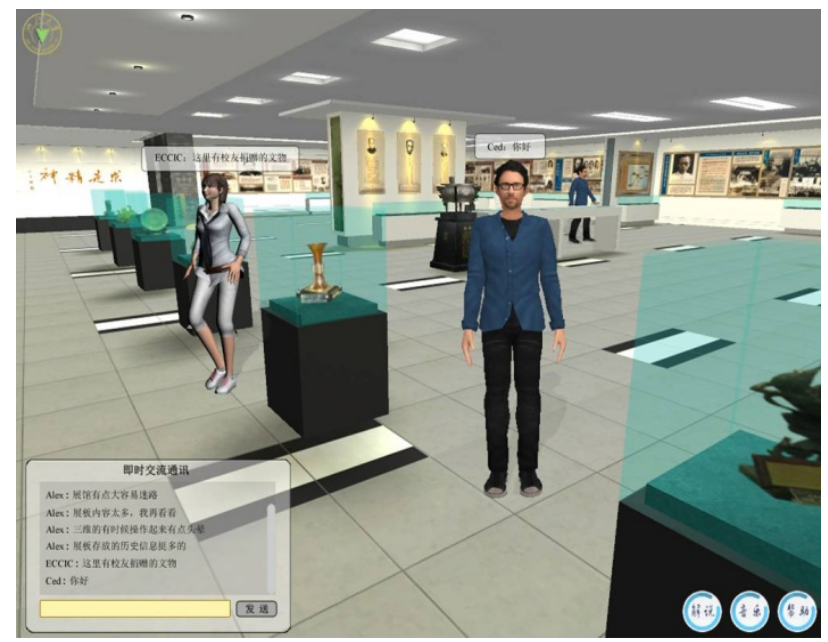

Figure 9. Cooperative learning of the digital history museum of Zhejiang University base on EUDMS 
TABLE II.

CONTRASTIVE ANALYSIS OF THE INFORMAL LEARNING EFFECT IN TWO DIFFERENT VIRSIONS OF DIGITAL HISTORY MUSEUM

\begin{tabular}{ccc}
\hline $\begin{array}{c}\text { Scores } \\
(\mathbf{1 0})\end{array}$ & $\begin{array}{c}\text { 3D digital history Museum } \\
\text { (X3D) }(\mathbf{n = 3 0})\end{array}$ & $\begin{array}{c}\text { 3D digital History Museum } \\
\text { (EUDMS) }(\mathbf{n}=\mathbf{3 0})\end{array}$ \\
\hline $0-4$ & $36.67 \%(11)$ & $10 \%(3)$ \\
$4-8$ & $60 \%(18)$ & $80 \%(24)$ \\
$9-10$ & $3.33 \%(1)$ & $10 \%(3)$ \\
\hline
\end{tabular}

TABLE III.

CONTRASTIVE ANALYSIS OF THE EVALUATION AND FEEDBACK IN TWO DIFFERENT VIRSIONS OF DIGITAL HISTORY MUSEUM

\begin{tabular}{lcc}
\hline \multicolumn{1}{c}{ Index } & $\begin{array}{c}\text { 3D digital history } \\
\text { Museum (X3D) }\end{array}$ & $\begin{array}{c}\text { 3D digital History } \\
\text { Museum } \\
\text { (EUDMS) }\end{array}$ \\
\hline $\begin{array}{l}\text { Easier management style } \\
\text { More interesting } \\
\text { environment }\end{array}$ & $20.00 \%(6)$ & $80.00 \%(24)$ \\
$\begin{array}{l}\text { More immersed } \\
\text { environment }\end{array}$ & $26.67 \%(8)$ & $73.33 \%(22)$ \\
$\begin{array}{l}\text { Faster update rate for } \\
\text { knowledge }\end{array}$ & $40.00 \%(12)$ & $60.00 \%(18)$ \\
$\begin{array}{l}\text { More convenient for } \\
\text { Collaborative learning }\end{array}$ & $6.67 \%(2)$ & $93.33 \%(28)$ \\
More exhibits & $16.67 \%(5)$ & $83.33 \%(25)$ \\
\hline
\end{tabular}

\section{CONCLUSIONS AND DISCUSSIONS}

Compared with the traditional university digital museum, an EUDMS has more advantages in editing the exhibits online, expanding the space of the museum, and providing convenience for developing various university digital museums. Abstract knowledge is transformed into specific 3D exhibits through the EUDMS, leading to easier understanding and acquisition of knowledge for the students. The cooperative management mode is popular with students, as it is more effective for informal learning. For online engineering, the development and educational application of the EUDMS provides a reference for the design of universal network software. The usage frequency and the speed of information dissemination were increased by the non-professional online editing and vivid knowledge representation.

\section{ACKNOWLEDGMENTS}

1. Zhejiang Province's Education Department's Project "New Design strategy and informal learning of university digital museum" [Y201329997].

2. Zhejiang Province's Education Department's Project "Integration of the Virtual and Actual Lab Environment and Its Applied Research in Medical Teaching" [Y201225600].

3. Health Department of Zhejiang province's Project "The development and application of interactive eye virtual experiment platform based on Web" [2012KYB064].

\section{REFERENCES}

[1] Wei, L., Dinghao, Z., Jiming, C., Jingui, P. Research on Key Techniques in Construction of Virtual Museum System. Computer Science (China). 2007. Vol 34.No7. Pp244-247.

[2] Isler, V., Wilson, B., Bajcsy, R. Building a 3D Virtual Museum of Native American Baskets.Third International Symposium on 3D Data Processing, Visualization, and Transmission. Chapel Hill, NC.IEEE Press.2006. Pp954-961.
[3] Tsichritzis D, Gibbs S .Virtual museums and virtual realities. In: Proceedings of the International Conference on Hypermedia and Interactivity in Museums, Pittsburgh, PA, and October 1991.pp1416.

[4] Stytz, M.: Distributed Virtual Environment. J. IEEE Computer Graphics and Application16 (3), 1996. 19-31.

[5] Martínez, E., Jiménez, E., Sanz, F., Pérez, M., Blanco, J., Santamaría, J. Virtual representation of terrain through the web with VRML-Web3D and graphic libraries. In: International Journal on Interactive Design and Manufacturing (IJIDeM).2010. Vol 4 .pp125-136. http://dx.doi.org/10.1007/s12008-010-0094-4

[6] Jianping, Z., Yuhui, Y.: Design and Implementation of Virtual Museum Based onWeb3D. Transactions on Edutainment III, v 5940 LNCS, 2009. pp. 154--165

[7] Wei, L., Sourin, A., Stocker, H. Collaboration in 3D Shared Spaces Using X3D and VRML. IEEE Press. Bradford .2009. Pp36-42.

[8] Yan, Z., Weiling, L., Liang, L.: Building the Virtual Reality GIS Based on Browser/Service. In: Geoinformatics, 2011 19th International Conference on. Published by IEEE. Shanghai. 2011. pp:1-4

[9] Web3D Consortium | Open Standards for Real-Time 3D, http://www.web3d.org

[10] Carrozzinoa, M., Brunob, N., Bergamascoa, M. Designing interaction metaphors for Web3D cultural dissemination. Journal of Cultural Heritage, 2013.Vol14, pp146-155 http://dx.doi.org/10.1016/j.culher.2012.01.009

[11] Tokyo University Digital Museum. http://www.um.u-tokyo.ac.jp/.

[12] Harvard Art Museums. http://www.harvardartmuseums.org/.

[13] University of Pennsylvania Museum of Archaeology and Anthropology. http://www.penn.museum/.

[14] The digital museum of Tsinghua university. http://www .ex vpo.tsinghua.edu.cn/

[15] Jianxia, G., System Design of Virtual Human Science Museum. In: Proceedings of the 2012 International Conference on Communication, Electronics and Automation Engineering Advances in Intelligent Systems and Computing, Springer Berlin Heidelberg press. 2012. Vol 181.pp.851-858.

[16] Fabio, B., Stefano, B., Giovanna, D. S., Maria-Laura, L. From 3D reconstruction to virtual reality: A complete methodology for digital archaeological exhibition. Journal of Cultural Heritage 2010. Vol 11.pp42-49. http://dx.doi.org/10.1016/j.culher. 2009.02.006

[17] Krzysztof, W., Wojciech, R.W. Designing behavior-rich interactive virtual museum exhibitions.In: VAST'07 Proceedings of the 8th International conference on Virtual Reality, Archaeology and Intelligent Cultural Heritage.ACM digital library. Aire-la-Ville.2007. pp.101-108

[18] Angeloni, I., Bisio, F., De Gloria, A., Mori, D., Capurro, C., Magnani, L. A Virtual Museum for Flemish artworks. A digital reconstruction of Genoese collections. In: 2012 18th International Conference on Virtual Systems and Multimedia (VSMM), IEEE Press. Milan .2012. Pp.607-610.

[19] Takahashi, J., Kushi, T., Jung-Kook, H., Shigeharu, S., Yasuyuki, K. Global digital museum: multimedia information access and creation on the Internet.In: DL '98 Proceedings of the third ACM conference on Digital libraries, New York, 1998. Pp244-253.

[20] Instructional Technology/Edgar Dale. http://en.wikibooks.org/ wiki/Instructional_Technology/Edgar_Dale.

[21] Mahnaz Moallem, Ph.D. Applying Constructivist and Objectivist Learning Theories in the Design of A Web-Based Course: Implications for Practice. Educational Technology \& Society 4 (3) 2001. pp. 113-125.

[22] CAO Tong. 3D scene construction and interactive walkthrough design of virtual museum. Computer Engineering and Design.2007 (24). Pp.6006-6011.

[23] Jianghai Zhao. Designing Virtual Museum Using Web3D Technology. In: 2012 International Conference on Medical Physics and Biomedical Engineering (ICMPBE2012). Physics Procedia. Volume 33, 2012, pp.1596 - 1602.

[24] RG Wang, HL Dong, MW Wu, QF Wu. Research and Design of Digital Museum Based on Virtual Reality. Advanced Materials Research .Volumes 926-930.2014. Pp.2516-2520. 
[25] Tsung-Han Lee, Kuei-Shu Hsu,Long-Jyi Yeh. Design and Application of the Augmented Reality with Digital Museum and Digital Heritage. In: 6th International Conference on E-learning and Games, Edutainment 2011, Taipei. Edutainment Technologies. Educational Games and Virtual Reality/Augmented Reality Applications. press. Springer Berlin Heidelberg. 2011. pp. 25-26.

[26] Victoria J. Marsick, Karen E. Watkins. Informal and Incidental Learning New Directions for Adult and Continuing Education. Volume 2001, Issue 89，2001. Pp.25-34. http://dx.doi.org/ 10.1002/ace.5

[27] Jay Cross. Informal Learning: Rediscovering the Natural Pathways That Inspire innovation and performance. San Francisco, CA: Pfeiffer Publishing.

\section{AUTHORS}

Yang Yuhui is with the Modern Educational Technology Center of Zhejiang University, Hangzhou, and 310027 CHINA (e-mail: zju_edu@ 163.com).

Zhang Hao is with the Public Health College of Zhejiang University, Hangzhou, and 310058 CHINA (email: zju_medical@163.com).

Youbin Jiang (Corresponding author) is with the Modern Educational Technology Center of Zhejiang University, Hangzhou, and 310027 CHINA (e-mail: jiangyoubin@zju.edu.cn).

Submitted 05 June 2014. Published as resubmitted by the authors 25 January 2015. 